\title{
PLAG1 silencing promotes cell chemosensitivity in ovarian cancer via the IGF2 signaling pathway
}

\author{
WEI HUANG ${ }^{1}$, BI-RONG LI ${ }^{1}$ and $\mathrm{HAO} \mathrm{FENG}^{2}$ \\ Departments of ${ }^{1}$ Gynecology and ${ }^{2}$ Dermatology, Hunan Provincial People's Hospital, \\ The First Affiliated Hospital of Hunan Normal University, Changsha, Hunan 410005, P.R. China
}

Received August 28, 2018; Accepted August 12, 2019

DOI: $10.3892 /$ ijmm.2020.4459

\begin{abstract}
Ovarian cancer (OC) is one of the most lethal gynecological diseases. Novel prognostic biomarkers and therapeutic targets for $\mathrm{OC}$ are urgently required. The aim of this study was to investigate the mechanisms that govern how pleomorphic adenoma gene 1 (PLAG1) influences the biological processes and chemosensitivity of OC cells via the insulin-like growth factor-2 (IGF2) signaling pathway. Differentially expressed genes in OC were selected based on bioinformatics data. OC and adjacent tissue specimen were collected, followed by the determination of the expression of PLAG1 and IGF2 signaling pathway-associated genes. The regulatory mechanisms of PLAG1 in OC cells were analyzed following treatment with pcDNA or small interfering RNA (siRNA), and included the assessment of cell proliferation, migration, invasion and cisplatin resistance. PLAG1 was identified as an upregulated gene in OC. OC tissues exhibited increased expression of PLAG1 and IGF2 compared with the controls. Moreover, PLAG1 was observed to positively regulate the IGF2 signaling pathway. The siRNA-mediated silencing of PLAG1 resulted in decreased expression of IGF2, IGF1 receptor and insulin receptor substrate 1 , as well as inhibited proliferation, migration, invasion and cisplatin resistance of OC cells. Furthermore, the effect of PLAG1 was dependent on IGF2. PLAG1 may therefore be considered as a possible target for the treatment of $\mathrm{OC}$.
\end{abstract}

\section{Introduction}

Ovarian cancer (OC) is predominant among all types of gynecological cancer, and is widely geographical distributed in Asian countries with high incidence and morbidity $(1,2)$. Due

Correspondence to: Dr Hao Feng, Department of Dermatology, Hunan Provincial People's Hospital, The First Affiliated Hospital of Hunan Normal University, 61 Jiefang West Road, Changsha, Hunan 410005, P.R. China

E-mail: doctorfenghao@126.com

Key words: pleomorphic adenoma gene 1, insulin-like growth factor-2, ovarian cancer, proliferation, chemosensitivity to the aggressiveness, recurrence and drug-resistance of the disease, most OC patients are diagnosed at an advanced stage and have a poor prognosis (3). As predicted by the International Agency for Research on Cancer in 2018, the number of OC cases and $\mathrm{OC}$-associated deaths worldwide will rise by 55 and $67 \%$, respectively, over the next two decades (4). For patients with advanced OC, primary cytoreductive surgery in combination with a platinum agent (cisplatin)-based chemotherapy is the cornerstone of current treatment (5). However, the development of drug resistance frequently triggers tumor recurrence after chemotherapy in $57 \%$ of OC patients (6). Therefore, the molecular mechanisms involved in tumor chemoresistance and more efficacious consolidation strategies are acutely needed to improve progression-free and overall survival for patients with OC.

Pleomorphic adenoma gene 1 (PLAG1), located on chromosome $8 \mathrm{q} 12$, belongs to the pleomorphic adenoma (PLA) gene family and encodes a zinc finger protein with 2 putative nuclear localization signals (7). PLAG1-associated Gene Ontology annotations include DNA binding transcription factor activity and transcriptional activator activity (8). Previous studies have emphasized the positive role played by the overexpression of PLAG1 in tumor angiogenesis and development (9-11). Meanwhile, high expression of PLAG1 is reported to be an independent prognostic factor in hepatocellular carcinoma (12). Sun et al (13) demonstrated that knockdown of PLAG1 increased the tumor necrosis factor-related apoptosis-inducing ligand (TRAIL) sensitivity of acute myeloid leukemia cells. Mounting reports have illustrated an enhanced anticancer effect of TRAIL-cisplatin combination therapy (13-15). Insulin-like growth factor 2 (IGF2), which is a confirmed target of PLAG1, may be involved in the pathological process of OC (16). Furthermore, Zhuang et al (17) suggested that IGF1 receptor (IGF1R) is involved in the microRNA-143 (miR-143)-mediated resistance of gastric cancer cells to cisplatin. Insulin receptor substrate 1 (IRS1) is a classical adaptor protein for IGF1R (18). It has been speculated that IRS1 variants, which affect IGF and insulin signaling, modify OC risk in breast cancer 1 (BRCA1) and BRCA2 mutation carriers (19). Additionally, the IRS1/IGF1R signaling pathway regulates the resistance of human gastric cancer cells to cisplatin (20). Hence, we hypothesized that PLAG1 may represent a novel target in the therapy for $\mathrm{OC}$, with the involvement of the IGF2/IGF1R/IRS1 signaling pathway. 
In the present study, gene overexpression and silencing experiments were performed to investigate the role of PLAG1 in the cellular activities and cisplatin resistance of OC cells, and its underlying molecular mechanisms were investigated.

\section{Materials and methods}

Ethics statement. All patients enrolled in the study signed informed consent documentation. All experimental procedures were conducted under the approval of the Clinical Experiment Ethics Committee of Hunan Provincial People's Hospital (The First Affiliated Hospital of Hunan Normal University; Changsha, China).

Bioinformatics prediction. Based on the Gene Expression Omnibus database (http://www.ncbi.nlm.nih.gov/geo), the National Center for Biotechnology Information, datasets for GSE66957, GSE54388, GSE40595 and GSE18520 and annotation files associated to OC were retrieved and downloaded. Dataset information is depicted in Table I. The Affy 1.60.0 installation package (http://www.bioconductor. org/packages/release/bioc/html/affy.html) in $\mathrm{R}$ software 3.5.1 (https://www.r-project.org) was used to perform background correction and normalization processing of the data. Differential expression analysis was conducted for data profiling by the package limma 3.36.5 (http://master. bioconductor.org /packages/release/bioc/html/limma.html) in $\mathrm{R}$ software. The differentially expressed genes (DEGs) were screened out with an adjusted $\mathrm{P}<0.05$ and a threshold of $\log 2$ (fold change) $>2$. Next, heat maps of DEGs in dataset were drawn using the pheatmap package 1.0.10 (https://cran.r-project. org/web/packages/pheatmap/index.html) in R software, while the intersection of the four datasets was obtained using Jvenn (http://jvenn.toulouse.inra.fr/app/example.html) (21), which is an interactive Venn diagram viewer. DisGeNET (http://www. disgenet.org/web/DisGeNET/menu/search?4) is a relational gene-disease database that integrates information of human disease-associated genes and variants (22). OC associated genes were retrieved using 'Ovarian Carcinoma' as the keyword in the DisGeNET database. The STRING database (https://string-db.org/) was employed to extract protein-protein interaction data (23) and Cytoscape (3.6.0) was used for extracting DEG-OC gene interaction networks (24).

Study subjects. A total of 75 female OC patients who were admitted to the Department of Gynecology in Hunan Provincial People's Hospital (The First Affiliated Hospital of Hunan Normal University) between August 2015 to September 2017 were enrolled in the current study All patients were confirmed as OC by postoperative pathological examination. Moreover, no patient received radiotherapy, chemotherapy or immunotherapy before surgery. The age ranged from 21-64 years, with a mean age of $43.23 \pm 9.96$ years. OC and adjacent $(3 \mathrm{~cm})$ tissues were collected from all subjects and frozen in liquid nitrogen for further use. The stages of OC were determines according to the standard pathological staging system for OC (25).

Immunohistochemistry. Paraffin sections of OC and adjacent tissues $(4-6 \mu \mathrm{m})$ were dewaxed using xylene and dehydrated using gradient alcohol. Then, a 15-min treatment with 3\% hydrogen peroxide was conducted to eliminate endogenous peroxidases. The samples were subsequently blocked with normal goat serum (16210064; Gibco; Thermo Fisher Scientific, Inc.) for $20 \mathrm{~min}$ at $37^{\circ} \mathrm{C}$. After serum removal, samples were incubated with diluted primary rabbit PLAG1 antibody (1:1,000; ab80267; Abcam) at $4^{\circ} \mathrm{C}$ overnight, with PBS used as the negative control. After that, the samples were further incubated with goat anti-rabbit secondary HRP-conjugated IgG antibody (1:1,000; ab150117; Abcam) at $37^{\circ} \mathrm{C}$ for $30 \mathrm{~min}$. Streptavidin-biotin complex (Boster Biological Technology) was added to the samples according to the manufacturer's instructions and samples were incubated at $37^{\circ} \mathrm{C}$ for $30 \mathrm{~min}$. Diaminobenzidine $(1: 1,000)$ was utilized to develop the samples at room temperature for 15-20 min followed by counterstaining with hematoxylin $(0.3 \mathrm{~g} / \mathrm{ml})$ at room temperature for $1 \mathrm{~min}$ prior to observation under a light microscope (magnification, x200).

Cell culture and screening. OC cell lines A2780 (CBP60283), SKOV3 (CBP60291), HO8910 (CBP61086) and COC1 (CBP60776) were provided by Cobioer. RPMI-1640 (CBP50005; Gibco; Thermo Fisher Scientific, Inc.) containing $10 \%$ fetal bovine serum (FBS; Gibco; Thermo Fisher Scientific, Inc.) was used to suspend A2780, HO8910 and COC1 cells and SKOV3 cells were suspended using McCoy's 5A (CBP50013 Gibco; Thermo Fisher Scientific, Inc.) supplemented with $10 \%$ FBS. Then, the cells $\left(0.5 \times 10^{5} / \mathrm{ml}\right)$ were added to $24-$-well plates $(1 \mathrm{ml} /$ well $)$ and incubated at $37^{\circ} \mathrm{C}$ in an incubator with $5 \% \mathrm{CO}_{2}$ and $100 \%$ saturated humidity. The cells were passaged once every 2-3 days. Cell line screening included determining the expression levels of PLAG1 and IGF2 in the four cell lines by reverse transcription-quantitative (RT-q) PCR.

Small interfering RNA (siRNA) construction and screening. Three siRNAs sequences for each PLAG1 and IGF2, as well as a negative control (NC; Table II) were designed online (http://rnaidesigner.thermofisher.com/rnaiexpress/). The sequences were cloned into pRI-GFP/Neo plasmids (cat. no. V6408; Inovogen Biotechnology, Pvt., Ltd.). Following enzyme digestion by BamHI (ER0053; Thermo Fisher Scientific, Inc.) and HindIII (FD0505; Thermo Fisher Scientific, Inc.), the constructed plasmids were validated by sequencing and named as si-PLAG1-1, si-PLAG1-2, si-PLAG1-3, si-IGF2-1, si-IGF2-2 and si-IGF2-3. siRNAs were transfected into OC cells as described below. RT-qPCR was employed to determine PLAG1 and IGF2 expression in the cells.

Construction of overexpression vectors. PLAG1 and IGF2 sequences obtained from the NCBI (https://www.ncbi. nlm.nih.gov) were inserted into the overexpression vector pcDNA3-EGFP (cat. no. 13031; Addgene, Inc.) carrying ampicillin resistance. Through restriction enzyme digestion by BamHI and HindIII and sequencing, it was confirmed that the PLAG1 and IGF2 overexpression plasmids were successfully constructed, and samples were named pcDNA-PLAG1 and pcDNA-IGF2, respectively. pcDNA-PLAG1, pcDNA-IGF2 and NC vectors were transfected into OC cells as described below. RT-qPCR was used to detect the content of PLAG1 and IGF2 in cells. 
Table I. Human ovarian cancer-associated gene expression datasets from the GLP570 platform.

\begin{tabular}{|c|c|c|}
\hline Accession no. & Cancer type & Samples \\
\hline GSE66957 & Unknown & Ovarian carcinoma $(n=57)$; normal ovarian $(n=12)$ \\
\hline GSE54388 & Epithelial ovarian cancer & $\begin{array}{l}\text { Healthy ovarian surface epithelium }(n=6) \text {; high grade serous ovarian } \\
\text { cancer }(n=16)\end{array}$ \\
\hline GSE40595 & Epithelial ovarian cancer & $\begin{array}{l}\text { Epithelial tumor from high grade serous ovarian cancer }(n=32) \text {; } \\
\text { normal ovarian surface epithelium }(n=6)\end{array}$ \\
\hline GSE18520 & Papillary serous cystadenocarcinoma & $\begin{array}{l}\text { Advanced stage, high-grade primary tumor }(n=53) \text {; normal ovarian } \\
\text { surface epithelium }(n=10)\end{array}$ \\
\hline
\end{tabular}

Table II. Sequences of designed siRNA and NC.

\begin{tabular}{ll}
\hline Construct & \multicolumn{1}{c}{ Sequence (5'-3') } \\
\hline si-PLAG1-1 & GCTGGAGGCAGATGTATAT \\
si-PLAG1-2 & GGAGGCAGATGTATATGAT \\
si-PLAG1-3 & CCAGCAACACTGACAACAA \\
si-IGF2-1 & TCGTGCTGCTCGTCTTCTT \\
si-IGF2-2 & TCGTGCTGCTATGCTGCTT \\
si-IGF2-3 & GGGCAAGTTCTTCCGCTAT \\
NC-1 & TTCTCCGAACGTGTCACGTTT \\
NC-2 & TTAAGAGGCTTGCACAGTGCA
\end{tabular}

siRNA, small interfering RNA; NC, negative control; PLAG1, pleomorphic adenoma gene 1 ; IGF2, insulin-like growth factor- 2 .

Grouping and transfection. A2780 used in the subsequent experiments and the following groups were established: Blank, not transfected; pcDNA-NC, transfected with empty vector; pcDNA-PLAG1, transfected with PLAG1 overexpression sequence; pcDNA-IGF2, transfected with IGF2 overexpression sequence; si-NC, transfected with empty siRNA vector; si-PLAG1, transfected with si-PLAG1; si-IGF2, transfected with si-IGF2; si-PLAG1 + pcDNA-IGF2, co-transfection with si-PLAG1 and IGF2 overexpression sequence; and pcDNA-PLAG1 + si-IGF2, co-transfected with PLAG1 overexpression sequence and si-IGF2.

Prior to transfection, cells $\left(4 \times 10^{5}\right.$ cells/well) were cultured in $500 \mu \mathrm{l}$ of antibiotic-free medium. When cell confluence reached $80 \%$, cells were transfected with Lipofectamine2000 (Invitrogen; Thermo Fisher Scientific, Inc.) according to the manufacturer's instructions. Serum-free medium $(50 \mu \mathrm{l})$ was used to dilute 20 pmol plasmid. Another $50 \mu \mathrm{l}$ of serum-free medium was used to dilute $1 \mu \mathrm{l}$ of transfection reagent and the mixture was incubated at room temperature for $5 \mathrm{~min}$. Then, both mixtures were combined and added to the individual wells for $6 \mathrm{~h}$. Complete medium was adopted and cells were further cultured at $37^{\circ} \mathrm{C}$ for $48 \mathrm{~h}$; A2780 cells at 3rd passage were used for subsequent experiments. The transfection efficiency of pcDNA-PLAG1, si-PLAG1, pcDNA-IGF2 and si-IGF2 is presented in Fig. S1.

EdU labeling. A2780 cells $\left(1 \times 10^{5} / \mathrm{ml}\right)$ were seeded in 24-well plates $(1 \mathrm{ml} /$ well $)$ with a cover glass coated with poly-lysine.
Cell culture medium was used to dilute EdU solution (C01503; 1:1,000; $50 \mu \mathrm{M}$; Shanghai Dongsheng Biotechnology Co., Ltd.). A total of $100 \mu \mathrm{l}$ of EdU culture medium $(50 \mu \mathrm{M})$ added to each well and incubated for $2 \mathrm{~h}$ with glycine $(2 \mathrm{mg} / \mathrm{ml})$ at room temperature for $10 \mathrm{~min}$. Next, $0.5 \%$ Triton X-100 $(100 \mu \mathrm{l})$ was added to each well to permeabilize cells and stain them with Apollo staining solution (100 $\mu \mathrm{l}$; Beyotime Institute of Biotechnology) at room temperature in the dark for $30 \mathrm{~min}$. Nuclei were stained with DAPI $(10 \mu \mathrm{g} / \mathrm{ml}$; C0060; Beijing Solarbio Science \& Technology Co., Ltd.) at room temperature for $10 \mathrm{~min}$ and observed under an inverted fluorescence microscope (magnification, $\mathrm{x} 200$ ). The proportion of DAPI-positive to EdU-positive cells was regarded as the positive cell rate.

Transwell assay. Matrigel was melted at $4^{\circ} \mathrm{C}$ overnight and diluted with serum-free medium (1:1). The solution was then added to a Transwell chamber for coating at room temperature for 15-30 min. Then, 2\% serum-containing medium was added to the cells to prepare cell a suspension, which was added to the upper chamber. The lower Transwell chamber contained medium supplemented with $20 \% \mathrm{FBS}$. After $20-24 \mathrm{~h}$ at $37^{\circ} \mathrm{C}$, the Transwell plate was immersed in formalin at room temperature for $10 \mathrm{~min}$. Subsequently, $0.1 \%$ crystal violet was used for staining at room temperature for 20-30 $\mathrm{min}$. We randomly selected five visual fields from each sample and the mean number of cells was calculated using an inverted microscope (magnification, x200) as the index of cell invasion ability.

Scratch test. Uniform horizontal lines were drawn on the back of 6-well plates every $0.5-1.0 \mathrm{~cm}$; each well was crossed by $\geq 5$ lines. A2780 cells $\left(5 \times 10^{5}\right)$ were added to 6 -well plates and grown to confluence of $95 \%$ over night. The next day, cell monolayers were scratched perpendicular to the horizontal lines using a $10 \mu \mathrm{l}$ pipette tip. Afterward, the cells were washed three times with PBS to remove cells. Each well was incubated with serum-free medium in a $5 \% \mathrm{CO}_{2}$ at $37^{\circ} \mathrm{C}$. Images were captured at 0 and $24 \mathrm{~h}$ using an optical microscope (magnification, $\mathrm{x} 200$ ).

CCK-8 assay. First, we used 10\% FBS medium to obtain various cisplatin (P4394-25MG; Sigma-Aldrich; Merck $\mathrm{KGaA})$ concentrations $(0,0.75,1.5,3,6$ and $12 \mu \mathrm{mol} / \mathrm{l})$ and stored it at $4^{\circ} \mathrm{C}$ for further use. A2780 cells $\left(2 \times 10^{4} / 200 \mu \mathrm{l}\right)$ at the logarithmic growth phase were added to a 96-well plate. The plate was incubated at $37^{\circ} \mathrm{C}$ with $5 \% \mathrm{CO}_{2}$ for $6 \mathrm{~h}$. Cisplatin $(1,000 \mu \mathrm{M})$ was diluted to $0.75,1.5,3,6$ and $12 \mu \mathrm{M}$ 
and added to wells, with three replicates for each concentration. Blank wells were used as controls. After $48 \mathrm{~h}$ incubation, $10 \mu 1$ fresh CCK-8 reagent (Yeasen) was added to each well, followed by $4 \mathrm{~h}$ incubation at $37^{\circ} \mathrm{C}$. Absorption (A) at $450 \mathrm{~nm}$ was detected and the cell survival rate was calculated as: [A(experimental)/A(control)] x100\%.

$R T$ - $q P C R$. total RNA was extracted from A2780 cells using TRIzol ${ }^{\circledR}$ reagent (Invitrogen; Thermo Fisher Scientific, Inc.) and the concentration and purity were determined. The total RNA was reverse transcribed into cDNA according to the instructions of the ReverTra Ace qPCR RT kit (Toyobo Life Science). Primers (Table III) were synthesized by Sangon Biotechnology Co., Ltd. qPCR was performed using a two-step method using a ReverTra Ace qPCR RT kit (Toyobo Life Science), GAPDH served as the internal reference. Each sample was measured three times and the data were analyzed using the $2^{-\Delta \Delta \mathrm{Cq}}$ method (26).

Western blot analysis. RIPA lysis buffer (Beyotime Institute of Biotechnology) and phenylmethylsulfonyl fluoride were added to A2780 cells to extract the total protein. The protein concentration was measured using a bicinchoninic acid kit. Then, $20 \mu \mathrm{g}$ protein was separated on $10 \%$ SDS-PAGE gels and transferred to polyvinylidene fluoride membranes. Each membrane was blocked using 5\% skimmed milk for $1.5 \mathrm{~h}$ at room temperature and then incubated with following rabbit primary antibodies: PLAG1(1:10,000; ab80267), IGF2 (1:1,000; ab9574), IGF1R (1:1,000; ab39398), IRS1 (1:1,000; ab52167) and GAPDH (1:2,500; ab9485). Then, membranes were incubated with horseradish peroxidase-conjugated goat anti-rabbit secondary IgG antibody (1:10,000; ab6721) at room temperature for $2 \mathrm{~h}$. All antibodies were purchased from Abcam. An enhanced chemiluminescence reagent (Shanghai Huiying Biological Technology Co., Ltd.) was used for sample development and imaging. Quantity One V4.6.6 software (Bio-Rad Laboratories, Inc.) for analyzing the gray value of each protein band.

Statistical analysis. Statistical analysis was performed using SPSS 21.0 (IBM Corp.). Data are expressed as the mean \pm standard deviation. All data were tested for normality and homogeneity of variance. If conforming to a normal distribution or homogeneity of variance, comparisons within the group were performed by paired Student's t-test, while comparisons between two groups were analyzed by an unpaired Student's t-test. Comparisons among multiple groups were assessed by one-way ANOVA with Tukey's post hoc test. If data did not conform to a normal distribution or homogeneity of variance, the rank sum test was used. Pearson's correlation coefficient was used to analyze the correlation between PLAG1 and IGF2. $\mathrm{P}<0.05$ was indicative of statistical significance.

\section{Results}

PLAG1 and IGF2 gene expression is increased in OC. DEGs associated with $\mathrm{OC}$ were extracted from four OC microarray datasets (GSE66957, GSE54388, GSE40595 and GSE18520). Venn diagrams (Fig. 1A) were drawn based on the top 600 DEGs in each dataset, presenting 10 genes (KLHL14, EPCAM,
Table III. Primer sequences for reverse transcriptionquantitative PCR.

\begin{tabular}{|c|c|c|}
\hline Gene & Direction & Sequence $\left(5^{\prime}-3^{\prime}\right)$ \\
\hline \multirow[t]{2}{*}{ PLAG1 } & Forward & ATCACCTCCATACACACGACC \\
\hline & Reverse & AGCTTGGTATTGTAGTTCTTGCC \\
\hline \multirow[t]{2}{*}{ IGF2 } & Forward & GTGGCATCGTTGAGGAGTG \\
\hline & Reverse & CACGTCCCTCTCGGACTTG \\
\hline \multirow[t]{2}{*}{ IGF1R } & Forward & TCGACATCCGCAACGACTATC \\
\hline & Reverse & CCAGGGCGTAGTTGTAGAAGAG \\
\hline \multirow[t]{2}{*}{ IRS1 } & Forward & ACAAACGCTTCTTCGTACTGC \\
\hline & Reverse & AGTCAGCCCGCTTGTTGATG \\
\hline \multirow[t]{2}{*}{ GAPDH } & Forward & ССССТТСАТТGАССТСААСТАСАТ \\
\hline & Reverse & TCACCATCTTCCAGGAGCG \\
\hline
\end{tabular}

PLAG1, pleomorphic adenoma gene 1; IGF2, insulin-like growth factor-2; IGF1R, IGF1 receptor; IRS1, insulin receptor substrate 1.

ELF3, CD24, SOX17, CRABP2, MST1, ESRP1, GIPC2 and PLAG1) in the dataset intersection. These genes were assessed in the subsequent analysis. In the DisGeNET dataset, we retrieved OC-associated genes and selected the top 20 genes (TP53, BRCA1, BRCA2, ERBB2, VEGFA, MUC16, EGFR, NBR1, PIK3CA, ESR1, PIK3CB, PIK3CD, PIK3CG, ABCB1, TSC1, EGF, AKT1, TNF, PARP1 and PGR) as OC-associated genes. DEGs in OC and OC-associated genes were applied in the STRING dataset to analyze the gene interaction. The gene interaction network was visualized via Cytoscape (Fig. 1B). In the interaction network, EPCAM, ELF3, PLAG1, MST1 and CRABP2 displayed a complex association (degree, $>5$ ) with other genes. Existing studies have revealed that EPCAM (27,28), ELF3 (29), MST1 (30), and CRABP2 (31,32) showed aberrant expression in OC. However, few studies have focused on the aberrant expression of PLAG1 in OC. Heat maps (Fig. 1C) of the top 100 DEGs in GSE54388 were prepared, indicating that PLAG1 was robustly overexpressed in OC compared with normal tissues. As shown for the GSE66957, GSE40595 and GSE18520 datasets (Fig. 2A-C), PLAG1 was overexpressed in OC tissues. The expression of IGF2 was abundant in OC, as previously described $(33,34)$. Of importance, PLAG1, as a transcriptional activator of IGF2, regulates expression of IGF2 (35). It was hypothesized that PLAG1 may serve a role in the progression of OC that may also affect IGF2 expression.

PLAG1 and IGF2 are overexpressed in OC tissues. RT-qPCR was utilized to determine the expression of PLAG1 and IGF2 in the $75 \mathrm{OC}$ and corresponding adjacent tissues. Of the 75 patients a total of 36 cases were confirmed to be stage I, 28 stage II and 11 stage III. A total of 39 cases were ovarian serous adenocarcinomas, 23 cases were mucinous adenocarcinomas and 13 cases were endometrioid carcinomas. Compared with the adjacent tissues, the OC tissues showed significantly higher mRNA expression of PLAG1 and IGF2 $(\mathrm{P}<0.05$; Fig. 3A and $\mathrm{B})$. Correlation analysis displayed that expression levels of PLAG1 and IGF2 were positively correlated (Fig. 3C). Immunohistochemistry was employed to 


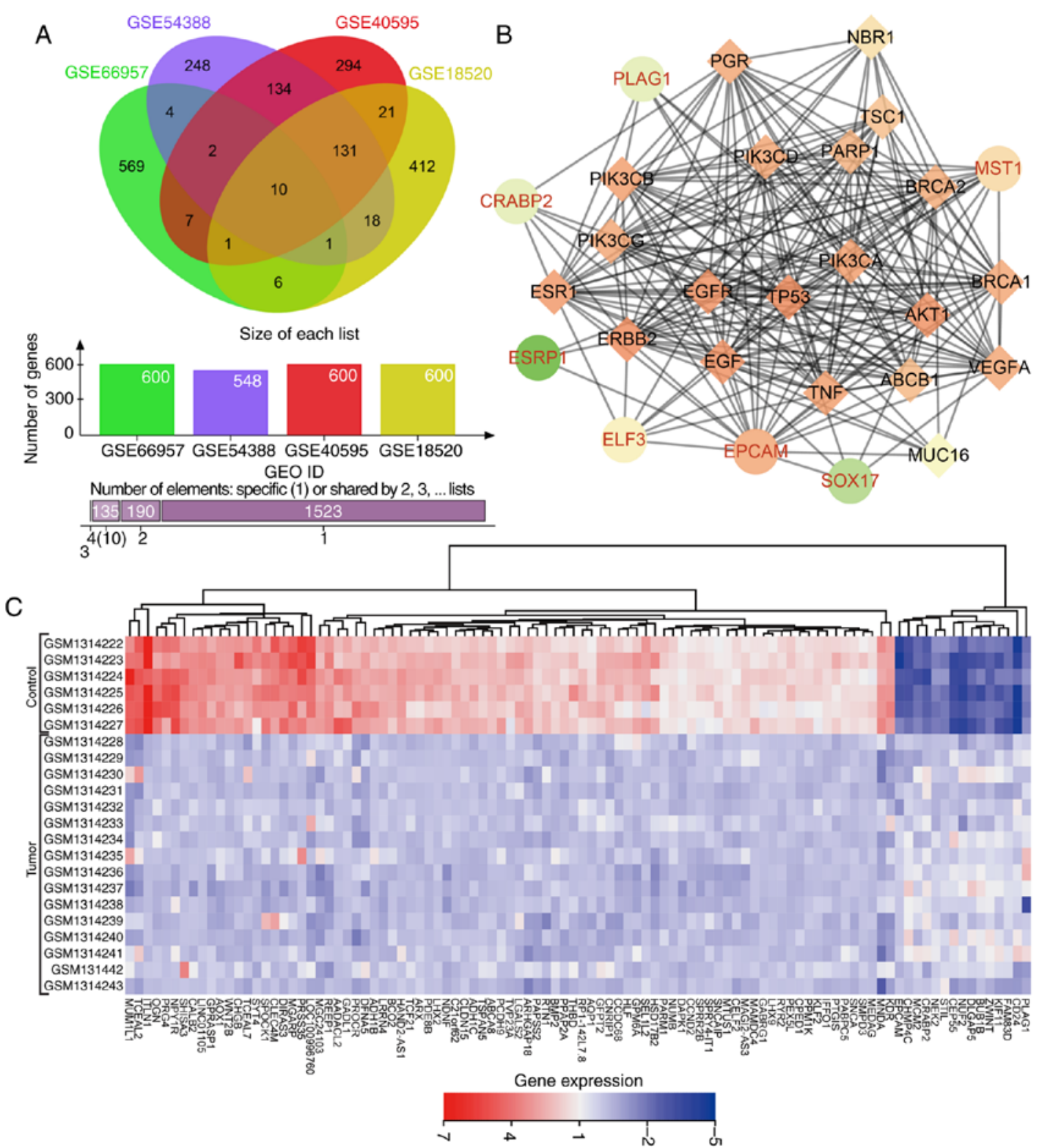

Figure 1. PLAG1 regulates IGF2 in OC. (A) Venn diagram of the top 600 DEGs in OC-associated gene expression datasets GSE66957, GSE54388, GSE40595 and GSE18520. Data are presented as: The ovals representing datasets; the number of genes per dataset; the number of elements specific for one dataset or shared by 2, 3 or 4. (B) Interaction network of DEGs and OC genes; circles denote DEGs in OC and diamonds represent OC-associated genes. (C) Heat map of the top 100 DEGs in the microarray dataset GSE54388. DEGs, differentially expressed genes; OC, ovarian cancer; PLAG1, pleomorphic adenoma gene 1; IGF2, insulin-like growth factor-2.
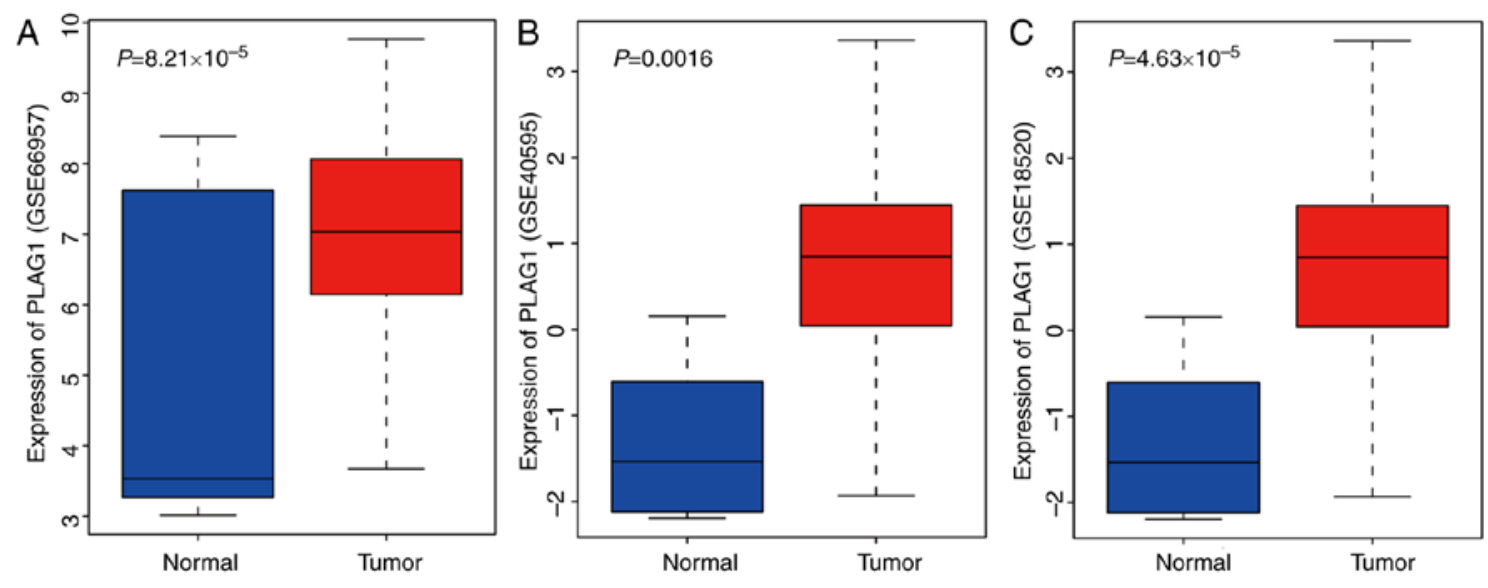

Figure 2. PLAG1 expression is increased in OC-associated gene expression datasets. Expression of PLAG1 in (A) GSE66957, (B) GSE40595 and (C) GSE18520. OC, ovarian cancer; PLAG1, pleomorphic adenoma gene 1. 

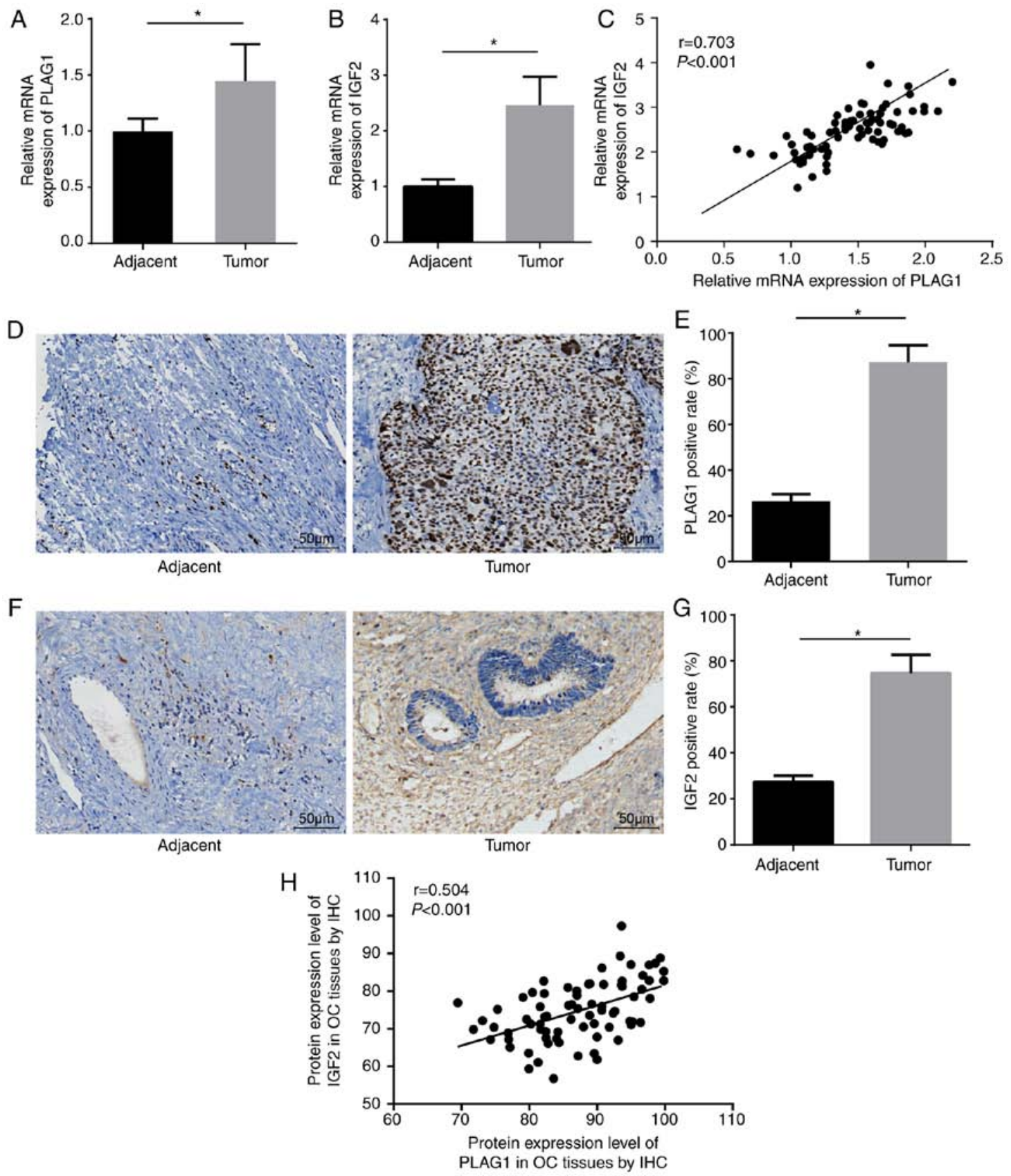

Figure 3. PLAG1 and IGF2 are upregulated in OC tissues. mRNA expression of (A) PLAG1 and (B) IGF2 in OC tissues and adjacent tissues. (C) Correlation between PLAG1 and IGF2 expression in OC tissues. (D) PLAG1 protein expression in OC and adjacent tissues observed after immunohistochemistry (magnification, x200) and (E) positive expression rate of PLAG1. (F) IGF2 protein expression in OC and adjacent tissues observed after immunohistochemistry (magnification, x200) and (G) positive expression rate of IGF2. (H) Correlation of PLAG1 and IGF2 expression in OC tissues. Data are expressed as the mean \pm standard deviation; each experiment was independently repeated three times; $n=75$. " $\mathrm{P}<0.05$ vs. adjacent tissues. OC, ovarian cancer; PLAG1, pleomorphic adenoma gene 1; IGF2, insulin-like growth factor-2.

measure the expression of PLAG1 (Fig. 3D and E). PLAG1 protein presented as pale brown or yellow-brown and was mainly expressed in the nucleus. The expression of PLAG1 in OC tissues was significantly higher than in adjacent tissues $(\mathrm{P}<0.05)$. In addition, immunohistochemistry was used to test the protein expression of IGF2. The results showed that IGF2 protein was pale brown or yellow-brown. Compared with the adjacent tissues, the expression of IGF2 in OC tissues was significantly elevated $(\mathrm{P}<0.05$; Fig. $3 \mathrm{~F}$ and $\mathrm{G})$. The immunohistochemistry results of PLAG1 and IGF2 were adopted for the correlation analysis, which demonstrated that the protein expression levels of PLAG1 and IGF2 were positively correlated (Fig. 3H).

Selection of siRNAs and cell lines for subsequent experiments. A series of experiments were conducted to select the siRNA with the highest transfection efficiency and to select an OC cell line to ensure the highest accuracy of the results. Among four OC cell lines, A2780 presented the highest expression of PLAG1 and IGF2 (Fig. 4A). As displayed in Fig. 4B-D, A2780 transfected with si-PLAG1-3 showed significant reductions in the mRNA and protein levels of PLAG1 when compared 

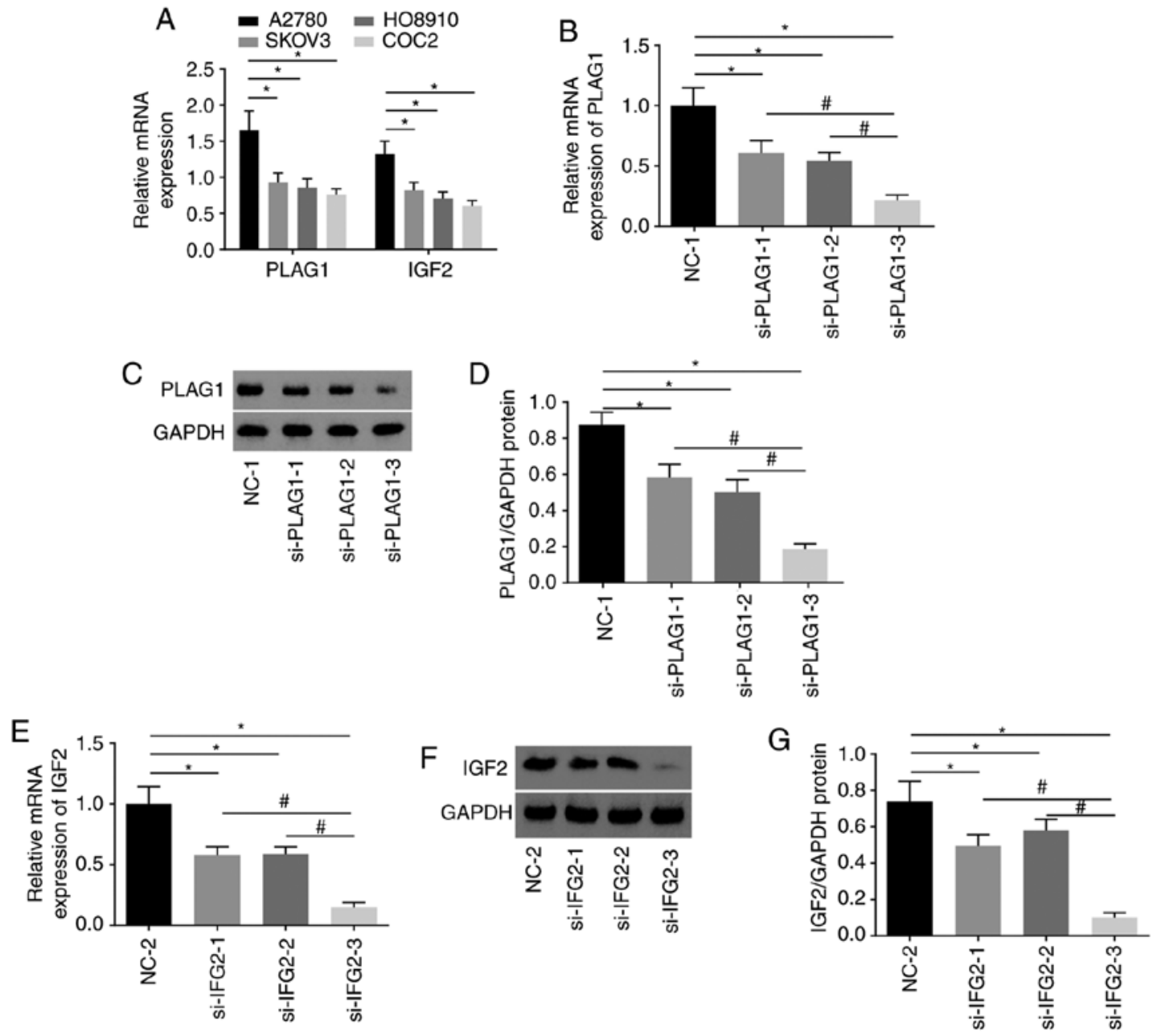

Figure 4. Silencing of PLAG1 and IGF2 in A2780 using siRNA. (A) Gene expression of PLAG1 and IGF2 in A2780, SKOV3, HO8910 and COC2 cell lines; ${ }^{*} \mathrm{P}<0.05$ vs. A2780. PLAG1 (B) mRNA expression, (C) western blot analysis and (D) protein quantification for OC cells transfected with three si-PLAG1s ${ }^{*} \mathrm{P}<0.05$ vs. NC-1; ${ }^{*} \mathrm{P}<0.05$ vs. si-PLAG1-3. IGF2 (E) mRNA expression, (F) western blot analysis and (G) protein quantification for OC cells transfected with three si-PIGF2s " $\mathrm{P}<0.05$ vs. NC-2; ${ }^{*} \mathrm{P}<0.05$ vs. si-PIGF2-3. Data are presented as the mean \pm standard error; each experiment was repeated three times. OC, ovarian cancer; PLAG1, pleomorphic adenoma gene 1; IGF2, insulin-like growth factor-2; si, small interfering RNA; NC, negative control.

with those transfected with si-PLAG1-1 and si-PLAG1-2 $(\mathrm{P}<0.05)$. The results suggested that A2780 transfected with si-IGF2-3 had significantly decreased mRNA and protein level of IGF2 compared with those transfected with si-IGF2-1 and si-IGF2-2 ( $\mathrm{P}<0.05$; Fig. 4E and G). The silencing effects of si-PLAG1-3 and si-IGF2-3 were the best among the tested siRNAs and A2780 transfected with si-PLAG1-3 and si-IGF2-3 were selected for subsequent experiments and are termed as si-PLAG1 and si-IGF2 hereafter.

PLAG1 activates the IGF2 signaling pathway. We conducted RT-qPCR to assess expression of IGF2 signaling pathway-associated genes to analyze the regulatory connection between PLAG1 and the IGF2 signaling pathway. The results suggested that overexpression of PLAG1 led to increased mRNA and protein expression of IGF2, IGF1R and IRS1, while silencing PLAG1 resulted in reversed observations for IGF2, IGF1R and IRS1 ( $\mathrm{P}<0.05$; Fig. 5). These findings suggested that PLAG1 positively regulated the IGF2 signaling pathway.

Silencing of PLAG1 suppresses proliferation, migration, invasion and cisplatin resistance in OC cells via downregulation of IGF2. EdU labeling, Transwell assay, scratch test and CCK8 assay were employed to evaluate cell proliferation (Fig. 6A and B), migration, invasion ability (Fig. 6C) and resistance to cisplatin (Fig. 6D), respectively. It was noted that no obvious differences in proliferation, migration and invasion ability, as well as resistance to cisplatin were displayed among the pcDNA-NC and si-NC groups $(\mathrm{P}>0.05)$. Compared with the pcDNA-NC group, the number of EdU-positive cells and the invasion and migration ability were elevated in the pcDNA-IGF2 group, accompanied by enhanced resistance to cisplatin in a dose-dependent manner $(\mathrm{P}<0.05)$. However, compared with the si-NC group, a significant decrease was found in the number of EdU-positive cells and in the invasion and migration ability in the si-IGF2 group, where resistance to cisplatin was decreased in a dose-dependent manner $(\mathrm{P}<0.05)$. These results revealed that IGF2 silencing was associated with reducing OC cell proliferation, migration, invasion and drug resistance. In order to determine the role of PLAG1 in OC cellular processes, cell proliferation (Fig. 7A and B), migration, invasion (Fig. 7C) and drug resistance (Fig. 7D) were assessed. The number of EdU-positive cells, the invasion and migration ability, and 

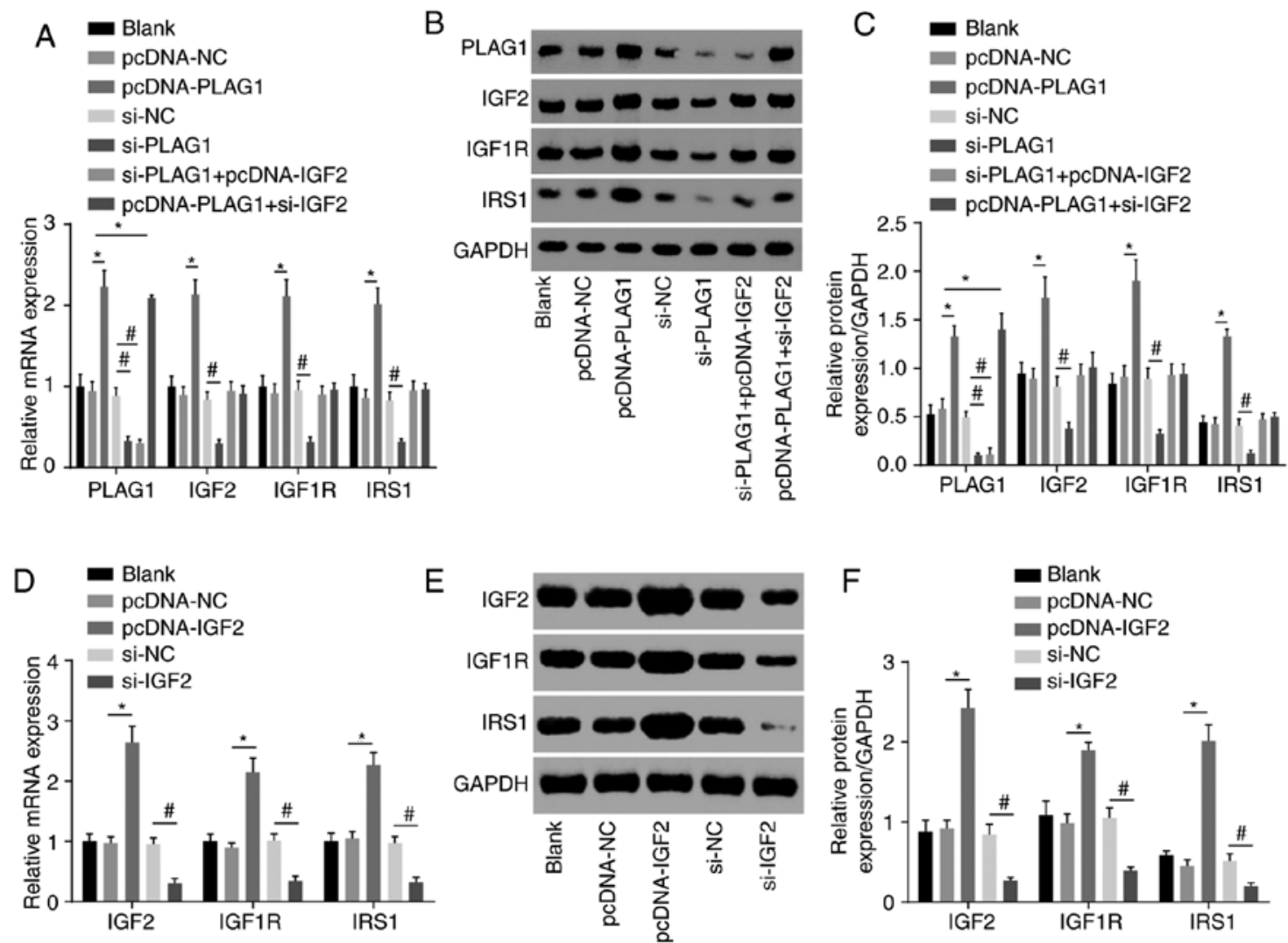

Figure 5. PLAG1 overexpression activates the IGF2 signaling pathway. PLAG1, IGF2, IGF1R and IRS1 (A) mRNA levels, (B) western blot images and (C) quantification in A2780 transfected with pcDNA-PLAG1, si-PLAG1, si-PLAG1 + pcDNA-IGF2 and pcDNA-PLAG1 + si-IGF2 or associated controls. IGF2, IGF1R and IRS1 (D) mRNA levels, (E) western blot images and (F) protein levels in A2780 transfected with pcDNA-IGF2 and si-IGF2 or respective controls. Data are expressed as the mean \pm standard error; each experiment was repeated three times. ${ }^{*} \mathrm{P}<0.05$ vs.pcDNA-NC; ${ }^{*} \mathrm{P}<0.05$ vs. si-NC. PLAG1, pleomorphic adenoma gene 1; IGF2, insulin-like growth factor-2; IGF1R, insulin-like growth factor 1 receptor; IRS1, insulin receptor substrate 1; si, small interfering RNA; NC, negative control.

A

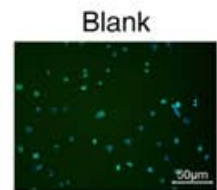

C
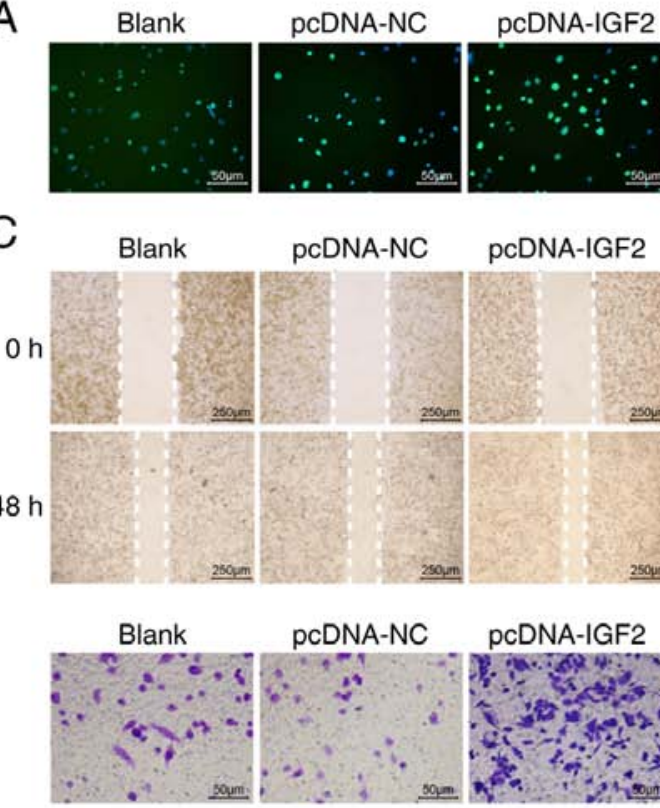
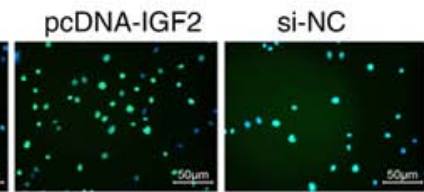

si-NC

si-NC

si-IGF2

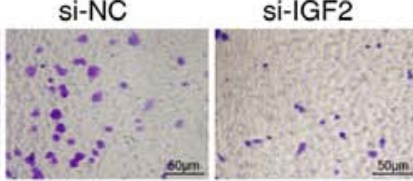

si-IGF2
$\mathrm{B}$
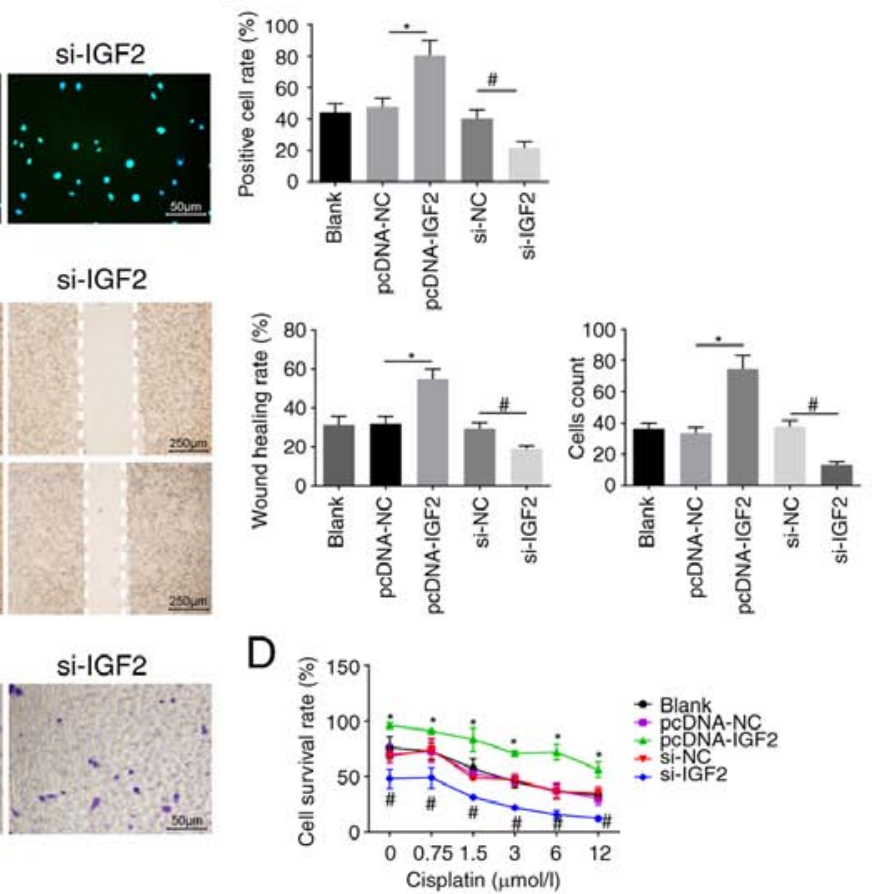

Figure 6. IGF2 promotes OC cell proliferation, migration, invasion and drug resistance. A2780 overexpressing or with silenced IGF2 were prepared. (A) EdU labeling (magnification, x200) and (B) EdU-positive cell rate. (C) Cell migration and invasion images (magnification, x200) and abilities. (D) Cell survival rates at different cisplatin concentrations. Data are expressed as the mean \pm standard error; each experiment was repeated three times. $\mathrm{P}<0.05$ vs. pcDNA-NC; ${ }^{\#} \mathrm{P}<0.05$ vs. si-NC. PLAG1, pleomorphic adenoma gene 1; IGF2, insulin-like growth factor-2; si, small interfering RNA; NC, negative control; OC, ovarian cancer. 


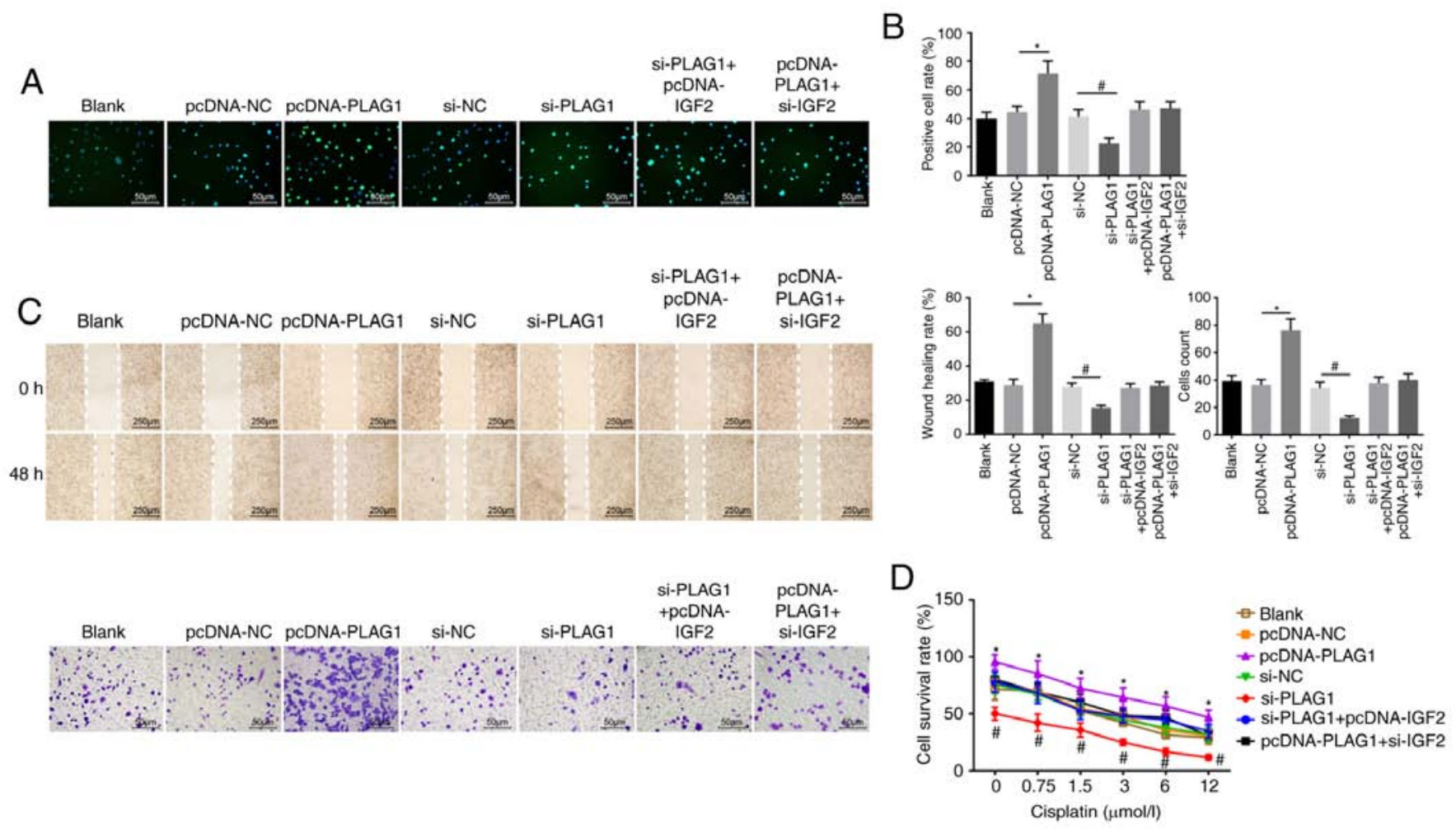

Figure 7. PLAG1 silencing represses OC cell proliferation, migration, invasion and drug resistance. A2780 overexpressing or with silenced PLAG1 were prepared. (A) EdU labeling (magnification, x200) and (B) EdU-positive cell rate. (C) Cell migration and invasion images (magnification, x200) and abilities. (D) Cell survival rates at different cisplatin concentrations. Data are expressed as the mean \pm standard error; each experiment was repeated three times. " $\mathrm{P}<0.05$ vs. pcDNA-NC; ${ }^{\#} \mathrm{P}<0.05$ vs. si-NC. PLAG1, pleomorphic adenoma gene 1; IGF2, insulin-like growth factor-2; si, small interfering RNA; NC, negative control; OC, ovarian cancer.

resistance to cisplatin were increased in the pcDNA-PLAG1 group compared with the pcDNA-NC group $(\mathrm{P}<0.05)$. Moreover, silencing of PLAG1 reversed these observed effects for A2780 overexpressing PLAG1 as suggested by the number of EdU-positive cells, the invasion and migration ability, and resistance to cisplatin. Results of the si-IGF2 + pcDNA-PLAG1 group were similar to the results for the si-PLAG1 + pcDNA-IGF2 group. Based on these results, we conclude that PLAG1 silencing reduced OC cell proliferation, migration, invasion and drug resistance by potentially affecting IGF2.

\section{Discussion}

OC, a heterogeneous group of malignant neoplasms, causes high mortality in females despite considerable progress in new cytotoxic drugs and targeted biologic agents (36-38). Metastasis is responsible for OC recurrence, and recurrent OC tumors are more aggressive and acquire resistance to conventional chemotherapeutic drugs $(39,40)$. Herein, we selected OC tissues and cells to elucidate the mechanism of PLAG1 regulation on the IGF2/IGF1R/IRS1 signaling pathway in OC and to investigate the underlying molecular alterations. In our study, gain- and loss-of-function assays demonstrated that the siRNA-mediated silencing of PLAG1 led to decreased migration, invasion capacity and cisplatin resistance; suggesting that the expression of PLAG1 may be associated with OC cell motility.

PLAG1 has been reported to be associated with the development of various malignant tumors, such as lung cancer (41) and chronic lymphoblastic leukemia (42). However, its role in OC has not been reported. We explored the expression and biological function of PLAG1 in OC. Through in vitro cell phenotypic experiments, it is suggested that PLAG1 functions as an oncogene. The oncogenic capacity of the PLAG1 gene has been previously demonstrated by in vivo/vitro approaches $(43,44)$. PLAG1 is usually overexpressed in PLA of the salivary gland due to fusion genes, including CTNNB1-PLAG1, with promoter swapping caused by chromosomal aberrations (11). Hypermethylation of the putative imprinting center region in OC shares an association with PLA gene like-1 (PLAGL1) expression levels (45). Sekiya et al (46) demonstrated that a PLAGL2 and PLAG1 structure- and function-associated family member induced activation of ras homolog family member A in OC cells, resulting in promoted organization of actin stress fibers and focal adhesions (47). It should be noted that the knockdown of PLAGL2 inhibited cell migration and invasion in breast cancer (48), which agrees with our results.

As a genuine transcription factor, PLAG1-encoded protein recognizes a specific bipartite DNA sequence motif and activates a variety of target genes in the IGF signaling pathway (49). Western blot analysis in the present study showed that PLAG1 modulated the expression of IGF2 and its associated proteins, IGF1R and IRS1. Furthermore, we confirmed that PLAG1 regulated the expression of IGF1R/IRS, thus promoting carcinogenesis in an IGF2-dependent manner. The fetal transcription factor PLAG1 was observed to be upregulated in cancers and has been indicated to bind to the IGF2 P3 promoter and to activate the IGF2 gene (50). Wang et al (51) employed a signal transduction microarray-based method to show that PLAG1 restoration is closely associated with IGF2 


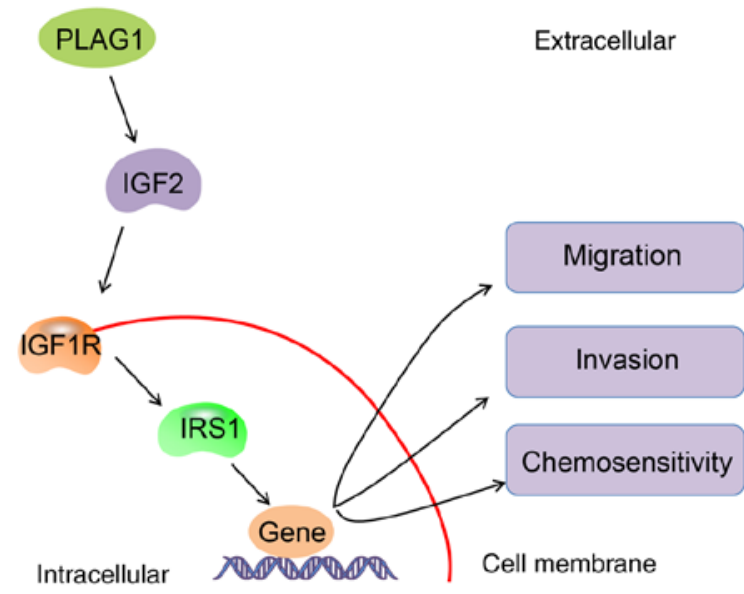

Figure 8. Molecular mechanisms involved in PLAG1 regulation in OC cells. PLAG1 activates the IGF2 signaling pathway in OC by upregulating IGF2, IGF1R and IRS1 and by accelerating migration and invasion, as well as repressing chemosensitivity of OC cells. PLAG1, pleomorphic adenoma gene 1; IGF2, insulin-like growth factor-2; IGF1R, insulin-like growth factor 1 receptor; IRS1, insulin receptor substrate 1; OC, ovarian cancer.

expression changes in transgenic mice. PLAG1 knockout mice and paternal IGF2-LOSS mice shared similar phenotypes, featured by intrauterine and postnatal growth retardation (35). IGF2 is considered as an unfavorable indicator of OC prognosis (52). IGF2 transcription from P3 and P4 promoters have a negative association with the survival of OC patients (53). IGF1 has been reported to exert a bystander effect for cisplatin resistance in various OC cells (54), which has been validated in the A2780 cell line. PLAG1, as an upstream regulator of IGF2, is resistant to cisplatin and may be developed as a new target for OC. Therefore, we explored the effect of PLAG1 on cisplatin resistance, and we found that PLAG1 conferred resistance to cisplatin. Taken together, our results suggest that PLAG1 may be a new therapeutic target in OC.

In conclusion, we found the abnormal expression of PLAG1 in several public databases. In addition, to verify the differential expression of PLAG1, we collected OC samples at different disease stages to obtain a more representative result. In the course of the study, we noted that different subtypes of OC have different prognoses. We did not use different cell lines for different subtypes of OC, which is one of the limitations of this study and further studies may be performed in the future. Moreover, future study may be investigated the mediators of the IGF1R signaling pathway to further explore whether PLAG1 directly causes sensitivity to cisplatin. Nevertheless, the key findings of our study presented significant evidence that PLAG1 was an oncogene in OC, and the knockdown of PLAG1 inhibited the metastatic potential of OC cells and sensitized OC cells to cisplatin by inactivating the IGF2/IGF1R/IRS1 signaling pathway (Fig. 8). These findings provide novel opportunities for PLAG1 as a potential therapeutic target in clinical settings. The repression of PLAG1 may reduce resistance of OC cells to chemotherapeutics, which may be of great clinical use in identifying effective therapeutic strategies for patients with OC.

\section{Acknowledgements}

Not applicable.

\section{Funding}

No funding was received.

\section{Availability of data and materials}

The data sets used and/or analyzed during the present study are available from the corresponding author on reasonable request.

\section{Authors' contributions}

WH and BRL designed the study. HF, WH and BRL collated the data, performed analyses and prepared the manuscript. All authors have read and approved the final submitted manuscript.

\section{Ethics approval and consent to participate}

All patients enrolled in the study signed informed consent documentation. All experimental procedures were conducted under the approval of the Clinical Experiment Ethics Committee of Hunan Provincial People's Hospital (The First Affiliated Hospital of Hunan Normal University; Changsha, China).

\section{Patient consent for publication}

Not applicable.

\section{Competing interests}

The authors declare that they have no competing interests.

\section{References}

1. Foster R, Buckanovich RJ and Rueda BR: Ovarian cancer stem cells: Working towards the root of stemness. Cancer Lett 338: 147-157, 2013.

2. Razi S, Ghoncheh M, Mohammadian-Hafshejani A, Aziznejhad H,Mohammadian M and Salehiniya H: The incidence and mortality of ovarian cancer and their relationship with the Human Development Index in Asia. Ecancermedicalscience 10: 628, 2016.

3. Mitra T, Prasad P, Mukherjee P, Chaudhuri SR, Chatterji U and Roy SS: Stemness and chemoresistance are imparted to the OC cells through TGF $\beta 1$ driven EMT. J Cell Biochem 119: 5775-5787, 2018

4. Manchanda R and Menon U: Setting the threshold for surgical prevention in women at increased risk of ovarian cancer. Int J Gynecol Cancer 28: 34-42, 2018.

5. Di Donato V, Kontopantelis E, Aletti G, Casorelli A, Piacenti I, Bogani G, Lecce F and Benedetti Panici P: Trends in mortality after primary cytoreductive surgery for ovarian cancer: A systematic review and metaregression of randomized clinical trials and observational studies. Ann Surg Oncol 24: 1688-1697, 2017.

6. Abu Hassaan SO: Monitoring ovarian cancer patients during chemotherapy and follow-up with the serum tumor marker CA125. Dan Med J 65, 2018.

7. Xu W, He H, Zheng L, Xu JW, Lei CZ, Zhang GM, Dang RH, Niu H, Qi XL, Chen H and Huang YZ: Detection of 19-bp deletion within PLAG1 gene and its effect on growth traits in cattle. Gene 675: 144-149, 2018.

8. https://www.genecards.org/cgi-bin/carddisp.pl?gene=PLAG1.

9. de Brito BS, Giovanelli N, Egal ES, Sanchez-Romero C, NascimentoJS,Martins AS, Tincani AJ,DelNegroA,GondakRO, Almeida OP, et al: Loss of expression of Plag1 in malignant transformation from pleomorphic adenoma to carcinoma ex pleomorphic adenoma. Hum Pathol 57: 152-159, 2016. 
10. Andreasen S, von Holstein SL, Homøe P and Heegaard S: Recurrent rearrangements of the PLAG1 and HMGA2 genes in lacrimal gland pleomorphic adenoma and carcinoma ex pleomorphic adenoma. Acta Ophthalmol 96: e768-e771, 2018.

11. Matsuyama A, Hisaoka M and Hashimoto H: PLAG1 expression in mesenchymal tumors: An immunohistochemical study with special emphasis on the pathogenetical distinction between sof tissue myoepithelioma and pleomorphic adenoma of the salivary gland. Pathol Int 62: 1-7, 2012

12. Hu ZY, Yuan SX, Yang Y, Zhou WP and Jiang H: Pleomorphic adenoma gene 1 mediates the role of karyopherin alpha 2 and has prognostic significance in hepatocellular carcinoma. J Exp Clin Cancer Res 33: 61, 2014.

13. Sun YP, Lu F, Han XY, Ji M, Zhou Y, Zhang AM, Wang HC, Ma DX and Ji CY: MiR-424 and miR-27a increase TRAIL sensitivity of acute myeloid leukemia by targeting PLAG1. Oncotarget 7: 25276-25290, 2016.

14. Xu L, Yin S, Banerjee S, Sarkar F and Reddy KB: Enhanced anticancer effect of the combination of cisplatin and TRAIL in triple-negative breast tumor cells. Mol Cancer Ther 10: 550-557,2011

15. Gasparian ME, Bychkov ML, Yagolovich AV, Kirpichnikov MP and Dolgikh DA: The effect of cisplatin on cytotoxicity of anticancer cytokine TRAIL and its receptor-selective mutant variant DR5-B ${ }^{1}$. Dok1 Biochem Biophys 477: 385-388, 2017.

16. Qian B, Katsaros D, Lu L, Canuto EM, Benedetto C, Beeghly-Fadiel A and Yu H: IGF-II promoter specific methylation and expression in epithelial ovarian cancer and their associations with disease characteristics. Oncol Rep 25: 203-213, 2011

17. Zhuang M, Shi Q, Zhang X, Ding Y, Shan L, Shan X, Qian J, Zhou X, Huang Z, Zhu W, et al: Involvement of miR-143 in cisplatin resistance of gastric cancer cells via targeting IGF1R and BCL2. Tumour Biol 36: 2737-2745, 2015.

18. Knowlden JM, Gee JM, Barrow D, Robertson JF, Ellis IO, Nicholson RI and Hutcheson IR: erbB3 recruitment of insulin receptor substrate 1 modulates insulin-like growth factor receptor signalling in oestrogen receptor-positive breast cancer cell lines. Breast Cancer Res 13: R93, 2011.

19. Ding YC, McGuffog L, Healey S, Friedman E, Laitman Y, Paluch-Shimon S, Kaufman B; SWE-BRCA, Liljegren A, Lindblom A, et al: A nonsynonymous polymorphism in IRS1 modifies risk of developing breast and ovarian cancers in BRCA1 and ovarian cancer in BRCA2 mutation carriers. Cancer Epidemiol Biomarkers Prev 21: 1362-1370, 2012

20. Yang M, Shan X, Zhou X, Qiu T, Zhu W, Ding Y, Shu Y and Liu P: miR-1271 regulates cisplatin resistance of human gastric cancer cell lines by targeting IGF1R, IRS1, mTOR, and BCL2. Anticancer Agents Med Chem 14: 884-891, 2014.

21. Bardou P, Mariette J, Escudié F, Djemiel C and Klopp C: Jvenn: An interactive Venn diagram viewer. BMC Bioinformatics 15 293, 2014

22. Piñero J, Bravo À, Queralt-Rosinach N, Gutiérrez-Sacristán A, Deu-Pons J, Centeno E, García-García J, Sanz F and Furlong LI DisGeNET: A comprehensive platform integrating information on human disease-associated genes and variants. Nucleic Acids Res 45: D833-D839, 2017.

23. Szklarczyk D, Franceschini A, Wyder S, Forslund K, Heller D, Huerta-Cepas J, Simonovic M, Roth A, Santos A, Tsafou KP, et al: STRING v10: Protein-protein interaction networks, integrated over the tree of life. Nucleic Acids Res 43: D447-D452, 2015.

24. Shannon P, Markiel A, Ozier O, Baliga NS, Wang JT, Ramage D, Amin N, Schwikowski B and Ideker T: Cytoscape: A software environment for integrated models of biomolecular interaction networks. Genome Res 13: 2498-2504, 2003

25. Chang SJ, Bristow RE and Ryu HS: Analysis of para-aortic lymphadenectomy up to the level of the renal vessels in apparent early-stage ovarian cancer. J Gynecol Oncol 24: 29-36, 2013.

26. Tuo YL, Li XM and Luo J: Long noncoding RNA UCA1 modulates breast cancer cell growth and apoptosis through decreasing tumor suppressive miR-143. Eur Rev Med Pharmacol Sci 19. 3403-3411, 2015.

27. Tayama S, Motohara T, Narantuya D, Li C, Fujimoto K Sakaguchi I, Tashiro H, Saya H, Nagano O and Katabuchi H: The impact of EpCAM expression on response to chemotherapy and clinical outcomes in patients with epithelial ovarian cancer. Oncotarget 8: 44312-44325, 2017.

28. Zheng J, Zhao S, Yu X, Huang S and Liu HY: Simultaneous targeting of CD44 and EpCAM with a bispecific aptamer effectively inhibits intraperitoneal ovarian cancer growth. Theranostics 7: 1373-1388,2017.
29. Quinn MC, Filali-Mouhim A, Provencher DM, Mes-Masson AM and Tonin PN: Reprogramming of the transcriptome in a novel chromosome 3 transfer tumor suppressor ovarian cancer cell line model affected molecular networks that are characteristic of ovarian cancer. Mol Carcinog 48: 648-661, 2009.

30. Shigemasa K, Hu C, West CM, Clarke J, Parham GP, Parmley TH, Korourian S, Baker VV and O'Brien TJ: p16 overexpression: A potential early indicator of transformation in ovarian carcinoma. J Soc Gynecol Investig 4: 95-102, 1997.

31. Toyama A, Suzuki A, Shimada T, Aoki C, Aoki Y, Umino Y, Nakamura Y, Aoki D and Sato TA: Proteomic characterization of ovarian cancers identifying annexin-A4, phosphoserine aminotransferase, cellular retinoic acid-binding protein 2 , and serpin B5 as histology-specific biomarkers. Cancer Sci 103: 747-755, 2012.

32. Cho H, Kang ES, Hong SW, Oh YJ, Choi SM, Kim SW, Kim SH, Kim YT, Lee KS, Choi YK and Kim JH: Genomic and proteomic characterization of YDOV-157, a newly established human epithelial ovarian cancer cell line. Mol Cell Biochem 319: 189-201, 2008

33. Dong Y, Li J, Han F, Chen H, Zhao X, Qin Q, Shi R and Liu J: High IGF2 expression is associated with poor clinical outcome in human ovarian cancer. Oncol Rep 34: 936-942, 2015.

34. Liefers-Visser JAL, Meijering RAM, Reyners AKL, van der Zee AGJ and de Jong S: IGF system targeted therapy: Therapeutic opportunities for ovarian cancer. Cancer Treat Rev 60: 90-99, 2017.

35. Abi Habib W, Brioude F, Edouard T, Bennett JT, Lienhardt-Roussie A, Tixier F, Salem J, Yuen T, Azzi S, Le Bouc Y, et al: Genetic disruption of the oncogenic HMGA2-PLAG1-IGF2 pathway causes fetal growth restriction. Genet Med 20: 250-258, 2018.

36. Zou Y, Wang F, Liu FY, Huang MZ, Li W, Yuan XQ, Huang OP and He M: RNF43 mutations are recurrent in Chinese patients with mucinous ovarian carcinoma but absent in other subtypes of ovarian cancer. Gene 531: 112-116, 2013.

37. Abramov Y, Carmi S, Anteby SO and Ringel I: Characterization of ovarian cancer cell metabolism and response to chemotherapy by (31)p magnetic resonance spectroscopy. Oncol Res 20: 529-536, 2013.

38. Karki R, Seagle BL, Nieves-Neira W and Shahabi S: Taxanes in combination with biologic agents for ovarian and breast cancers. Anticancer Drugs 25: 536-554, 2014

39. Wang W, Ren F, Wu Q, Jiang D, Li H, Peng Z, Wang J and Shi H: MicroRNA-497 inhibition of ovarian cancer cell migration and invasion through targeting of SMAD specific E3 ubiquitin protein ligase 1. Biochem Biophys Res Commun 449: 432-437, 2014.

40. Li C, Ding H, Tian J, Wu L, Wang Y, Xing Y and Chen M: Forkhead box protein C2 (FOXC2) promotes the resistance of human ovarian cancer cells to cisplatin in vitro and in vivo. Cell Physiol Biochem 39: 242-252, 2016.

41. Jin L, Chun J, Pan C, Kumar A, Zhang G, Ha Y, Li D, Alesi GN, Kang Y, Zhou L, et al: The PLAG1-GDH1 axis promotes anoikis resistance and tumor metastasis through CamKK2-AMPK signaling in LKB1-deficient lung cancer. Mol Cell 69: 87.e7-99.e7, 2018.

42. Pallasch CP, Patz M, Park YJ, Hagist S, Eggle D, Claus R, Debey-Pascher S, Schulz A, Frenzel LP, Claasen J, et al: miRNA deregulation by epigenetic silencing disrupts suppression of the oncogene PLAG1 in chronic lymphocytic leukemia. Blood 114: 3255-3264, 2009

43. Van Dyck F, Scroyen I, Declercq J, Sciot R, Kahn B, Lijnen R and Van de Ven WJ: aP2-Cre-mediated expression activation of an oncogenic PLAG1 transgene results in cavernous angiomatosis in mice. Int J Oncol 32: 33-40, 2008.

44. Declercq J, Van Dyck F, Braem CV, Van Valckenborgh IC, Voz M, Wassef M, Schoonjans L, Van Damme B, Fiette L and Van de Ven WJ: Salivary gland tumors in transgenic mice with targeted PLAG1 proto-oncogene overexpression. Cancer Res 65 : 4544-4553, 2005.

45. Arima T and Wake N: Establishment of the primary imprint of the HYMAI/PLAGL1 imprint control region during oogenesis. Cytogenet Genome Res 113: 247-252, 2006.

46. Sekiya R, Maeda M, Yuan H, Asano E, Hyodo T, Hasegawa H, Ito S, Shibata K, Hamaguchi M, Kikkawa F, et al: PLAGL2 regulates actin cytoskeletal architecture and cell migration. Carcinogenesis 35: 1993-2001, 2014.

47. Van Dyck F, Declercq J, Braem CV and Van de Ven WJ: PLAG1, the prototype of the PLAG gene family: Versatility in tumour development (Review). Int J Oncol 30: 765-774, 2007.

48. Xu B, Zhang X, Wang S and Shi B: MiR-449a suppresses cell migration and invasion by targeting PLAGL2 in breast cancer. Pathol Res Pract 214: 790-795, 2018 
49. Zhu J, Declercq J, Willekens K, Creemers J, Vermorken AJM and de Ven WJV: Abstract 1981: Interference of the polyphenolic compound curcumin with expression regulation of target genes of the PLAG1 oncogenic transcription factor. Cancer Res 72: 1981, 2012

50. Akhtar M, Holmgren C, Göndör A, Vesterlund M, Kanduri C, Larsson $\mathrm{C}$ and Ekström TJ: Cell type and context-specific function of PLAG1 for IGF2 P3 promoter activity. Int J Oncol 41: 1959-1966, 2012.

51. Wang Y, Shang W, Lei X, Shen S, Zhang H, Wang Z, Huang L, Yu Z, Ong H, Yin X, et al: Opposing functions of PLAG1 in pleomorphic adenoma: A microarray analysis of PLAG1 transgenic mice. Biotechnol Lett 35: 1377-1385, 2013.

52. Lu L, Katsaros D, de la Longrais IA, Sochirca O and Yu H: Hypermethylation of let-7a-3 in epithelial ovarian cancer is associated with low insulin-like growth factor-II expression and favorable prognosis. Cancer Res 67: 10117-10122, 2007.
53. Lu L, Katsaros D, Wiley A, Rigault de la Longrais IA, Puopolo M, Schwartz P and Yu H: Promoter-specific transcription of insulin-like growth factor-II in epithelial ovarian cancer. Gynecol Oncol 103: 990-995, 2006.

54. Eckstein N, Servan K, Hildebrandt B, Pölitz A, von Jonquières G, Wolf-Kümmeth S, Napierski I, Hamacher A, Kassack MU, Budczies J, et al: Hyperactivation of the insulin-like growth factor receptor I signaling pathway is an essential event for cisplatin resistance of ovarian cancer cells. Cancer Res 69: 2996-3003, 2009.

(i) (9) This work is licensed under a Creative Commons Attribution-NonCommercial-NoDerivatives 4.0 International (CC BY-NC-ND 4.0) License. 